\title{
Preparation of asymmetric gas separation membranes with high selectivity by a dual-bath coagulation method
}

\author{
J.A. van 't Hof, A.J. Reuvers, R.M. Boom, H.H.M. Rolevink and C.A. Smolders \\ University of Twente, Department of Chemical Engineering, P.O. Box 217, 7500 AE Enschede (Netherlands)
}

(Received September 9, 1991; accepted in revised form January 3, 1992)

\begin{abstract}
A new method for the preparation of gas separation membranes in a one-step procedure is presented, where common, non-volatile solvents can be used in the polymer solution. It concerns contacting of a polymer solution with two successive nonsolvent baths, whereby the first bath initiates the formation of a dense top layer and the second bath gives the actual polymer precipitation. Membranes made by this method will have high gas selectivity and do not need any additional coating. The new technique was used to make polyethersulfone (PES) hollow fibres from solutions consisting of $35 \%(\mathrm{w} / \mathrm{w})$ polymer and $10 \%$ glycerol in N-methylpyrrolidone (NMP). High selectivities were obtained when using glycerol or 1-pentanol as the first nonsolvent and water as the second one. For a feed gas of $25 \mathrm{vol} . \%$ of $\mathrm{CO}_{2}$ in methane the intrinsic selectivity of $\mathrm{PES}\left[\alpha\left(\mathrm{CO}_{2} / \mathrm{CH}_{4}\right) \approx 50\right]$ was easily obtained, without the necessity of an additional coating step. By a step-wise, liquid exchange removal of residual fluids in the fibres, an improvement in flux could be obtained. This was accompanied by a somewhat lower selectivity compared to that of directly air-dried fibres.
\end{abstract}

Keywords: fiber membranes; gas separations; membrane preparation and structure; asymmetric membranes; polyethersulfone

\section{Introduction}

Nowadays polymer membranes are used in a variety of gas separation processes, where they replace or are combined with more traditional methods like cryogenic distillation and absorption. Since the gases to be separated (e.g. $\mathrm{H}_{2}$ / $\mathrm{CO}, \mathrm{CO}_{2} / \mathrm{CH}_{4}$, and $\mathrm{O}_{2} / \mathrm{N}_{2}$ ) have comparable dimensions, separation is achieved by a so called solution-diffusion mechanism. This means that gases absorb into the membrane at the high

Correspondence to: Present address: J.A. van 't Hof, Permea Inc., 11444 Lackland Road, St. Louis, MO 63146 (USA). pressure (feed) side, diffuse across the membrane, and desorb at the low pressure (permeate) side. The permeation rate is proportional to the pressure difference over the membrane, the membrane area, and the permeability coefficient of the membrane material, and inversely proportional to the membrane thickness. The separation factor is determined by the relative rates of permeation. Since the permeability coefficient is dictated by the material used, and the driving force (i.e. the pressure difference) by the process conditions, the most important parameters in membrane fabrication are membrane area and thickness.

The largest membrane area per volume is ob- 
tained with hollow fibres, and currently fibres are almost exclusively used in gas separations.

To minimize the effective thickness, asymmetric membranes have been developed, consisting of a thin, selective skin, supported by a porous substructure of the same material. Loeb and Sourirajan were the first to make asymmetric membranes, suitable for desalination [1]. In their fabrication process a solution of cellulose acetate is cast as a thin film, and after a short evaporation time immersed in ice-water. Using this method of casting, evaporation, and immersion, Bouchilloux et al. [2], and Kimura [3] made the first gas selective membranes from various polymers. More recently, Peinemann and Pinnau used the same principle for polyethersulfone [4] and polyetherimide [5]. Pinnau and Koros [6] showed that flat membranes with high fluxes could be obtained, using solvent evaporation, having a dense skin less than $0.2 \mu \mathrm{m}$. In all these methods a partial solvent evaporation step prior to immersion in the nonsolvent is necessary to assure the formation of a gas-selective skin. The limitation of these 'evaporation' methods is of course the necessity of a volatile component in the polymer solution. Chlorinated hydrocarbons are often used to serve this purpose, which may necessitate the use of a non-aqueous coagulation bath to assure miscibility of solvent and nonsolvent upon immersion.

Another way to minimize the membrane thickness is the use of composite membranes. Here, a porous support material is coated with a thin layer of a second polymer. Depending on the porosity of the support, either the coating or the support determines the separation properties. An example of the second type is Monsanto/Permea's Prism ${ }^{\mathrm{TM}}$ membrane, where asymmetric polysulfone fibres are coated with a silicone rubber. It is believed that the coating material plugs defects in the base membrane, resulting in a multicomponent membrane where polysulfone is the separating material
$[7,8]$. Peinemann and Pinnau [4] employed the same idea, but here the coating is done on-line. The coating material (e.g. ethylcellulose, cellulose acetate-propionate or cellulose acetatebutyrate) is added to the nonsolvent bath, which in their case is methanol. Recent publications show a lot of activities in the field of fabrication of selective coatings [9-12]. Especially when polymers are used that are very expensive, or that can not be spun into fibres, this type of composites is preferred.

In our laboratory a new fabrication method for asymmetric gas separation membranes has been developed, in which neither solvent evaporation is needed during the formation process, nor a coating afterwards to obtain the desired separation properties. Membranes are formed by contacting a polymer solution with two nonsolvent baths in series. The first bath is used to obtain a concentrated layer of polymer at the interface (comparable to an evaporation step, as mentioned before), while the second bath is responsible for the actual coagulation (precipitation). The choice of both nonsolvents strongly depends upon the type of solvent present in the polymer solution.

In this publication the fabrication of gas selective asymmetric hollow fibres is described, using the dual-bath method. The demixing behaviour of a polymer solution in various nonsolvents (using light transmission experiments) was used to determine the type of nonsolvent needed in each of the immersion baths. With these data flat membranes were made to prove the concept, followed by the actual spinning. As the basis for this research the work by Reuvers et al. was used [13-15]. Our research effort has been focussed on the spinning of hollow fibres, which would have intrinsic selectivities without any coating procedure.

\section{Membrane formation}

Asymmetric membranes can be prepared in many ways [16], but nowadays the immer- 
sion-precipitation technique is commonly used. In this process a homogeneous solution, containing the membrane forming material (the polymer) and a solvent for the polymer, is cast as a thin film on a support or spun as a hollow fibre, and contacted with a nonsolvent for the polymer. By an exchange of solvent and nonsolvent the membrane is formed by demixing (phase separation) of the polymer solution and precipitation of the polymer (solidification). Both composition and temperature of the solution and of the coagulation bath determine the structure of the membrane. Variation of these parameters results in membranes with different structures, suitable for microfiltration, ultrafiltration, reverse osmosis, pervaporation or gas separation.

According to work by Reuvers et al. [13], the liquid-liquid demixing process in polymer solutions during membrane formation may proceed in two different ways, denoted as delayed demixing (type I) and instantaneous demixing (type II).

\section{Delayed demixing (type I)}

In case of delayed demixing there is a certain time interval between the moment of immersion of the polymer solution in the nonsolvent bath and the onset of demixing (phase separation). During this so called delay time there is a large outflow of solvent from the solution, while the inflow of nonsolvent is relatively small. These different diffusion rates are caused by an interplay between thermodynamic interaction parameters and friction coefficients $[14,17]$. The types of solvent and nonsolvent used play a major role in this process.

Because of a net loss of liquid (i.e. solvent) from the film, the polymer concentration at the interface increases considerably. This concentration will reach a value which is constant as long as no demixing takes place and as long as the film can be treated as semi-infinite [14].
Under these conditions the thickness of the concentrated layer increases with $\sqrt{ } t$, where $t$ is the contact time between polymer solution and nonsolvent bath. Only when the nonsolvent has reached the other side of the film, the local nonsolvent concentration in the film can exceed the minimum value necessary for liquid-liquid demixing. From kinetic measurements on nucleation in our laboratory by Ronner it is known that the degree of supersaturation, necessary to form nuclei of a diluted polymer phase, increases with increasing polymer concentration $[15,18]$. Because of the high polymer concentration at the interface nucleation of a diluted phase can hardly or not at all take place. After solidification in a later stage a dense top layer is formed. In the sublayer the polymer concentration is increasing as well, but to a lower extent. Although liquidliquid demixing can take place here, the increased polymer concentration hinders the growth of nuclei of the polymer lean phase. Furthermore, the amount of nonsolvent (and solvent) available in the nuclei will also be a limiting factor for growth. This may result in a structure of isolated pores (a closed cell structure), with a large resistance to (gas) transport.

Type I demixing is possible when the interaction between solvent and nonsolvent is poor. Examples of such combinations are acetone or tetrahydrofuran (THF) as a solvent and water as the nonsolvent, and $\mathrm{N}$-methylpyrrolidone (NMP), dimethylformamide (DMF), dimethylsulfoxide (DMSO) or N,N-dimethylacetamide (DMAc) as a solvent and higher alcohols (like butanol, pentanol or octanol) as the nonsolvent.

\section{Instantaneous demixing (type II)}

During instantaneous demixing liquid-liquid demixing occurs in the interfacial region as soon as the polymer solution is contacted with the nonsolvent bath. The ratio of the outflow 
of solvent to the inflow of nonsolvent is less extreme, as compared to type I demixing. Only a very thin interfacial layer with a high polymer concentration is formed. Although this results in a densified top layer, it usually contains imperfections and has no gas separation properties. The polymer concentration in the sub layer has hardly changed when the demixing process starts, and a relatively open substructure is formed. Only when high polymer concentrations are used (as in hollow fibre spinning) gas separation membranes can be obtained in this way. However, the flux through such membranes is very low.

Instantaneous demixing occurs when the interaction between solvent and nonsolvent is good. Examples are NMP, DMF, DMSO or DMAc as a solvent and water as nonsolvent.

Although the model for liquid-liquid demixing by Reuvers is based on a system with only three components (polymer, solvent and nonsolvent), it can be reasoned that addition of extra low molecular weight components (as is often done in membrane fabrication) will still result in two distinct types of demixing [15].

From the membrane properties obtained by the two types of demixing processes, it can be concluded that it is favourable to have a combination of both mechanisms; an increase of the polymer concentration over a short period during the delayed demixing process to get a dense top layer, rapidly followed by instantaneous demixing to achieve both a thin top layer and an open sub layer. This can be done by contacting the polymer solution during a relatively short time with a nonsolvent that has a poor interaction with the solvent. This contact time should preferably be shorter than the delay time, so that only a thin, concentrated polymer layer is formed at the interface, while the rest of the solution remains unchanged. When this film, with an anisotropic polymer distribution, is immersed in a second nonsolvent bath where instantaneous demixing can take place, the concentration at the interface is already too high to give liquid-liquid demixing and a dense structure is formed. The polymer concentration in the sub layer has not changed significantly yet and, therefore, an open, porous structure can be obtained.

As mentioned before, the thickness of the concentrated polymer layer at the interface increases with $\sqrt{ } t$ during the contact period with the first liquid, as long as no demixing takes place. This means that the top layer thickness of the final membrane will also increase with $\sqrt{ } t$. In order to produce an asymmetric membrane with a high flux, the immersion time in the first bath should be optimized. In other words, a residence time should be chosen which is short enough to obtain a thin top layer and which is long enough to ensure a defect-free top layer.

The type of demixing taking place in a certain polymer-solvent-nonsolvent system can be examined by a simple light transmission technique, shown in Fig. 1. A membrane is cast as a thin film on a glass plate and immediately immersed in a nonsolvent bath. Over the coagulation bath a simple desk lamp acts as a light source. After immersion, the light transmittance is measured as a function of time. Appearance of optical inhomogeneities in the film, as a result of demixing, causes the light transmittance to decrease.

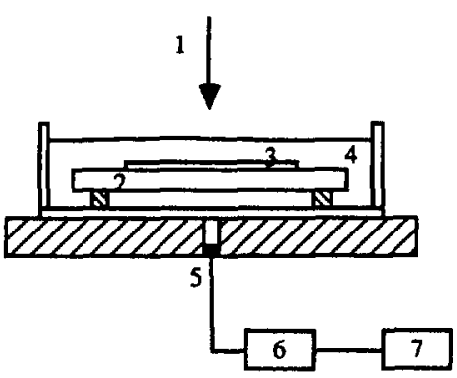

Fig. 1. Experimental set-up for light transmission measurements (from [13]). (1) light source, (2) glass plate, (3) polymer solution, (4) nonsolvent bath, (5) detector, (6) amplifier, (7) recorder. 
When the transmittance decreases as soon as the film is immersed in the coagulation bath, the type of demixing is defined as instantaneous (type II). When a 'delay time' between immersion and decrease of transmittance is observed, the demixing process is defined as delayed (type I). Both types of demixing are shown schematically in Fig. 2.

In practical use there are some limitations for the method of two successive nonsolvent baths ('dual-bath method'). Reuvers [19] stated that contact times in the first nonsolvent bath should be about one second or maybe even less. This means that rather high casting speeds (in flat membrane production) or high spinning speeds (in hollow fibre preparation) are necessary. Furthermore, the nascent membrane leaving the first nonsolvent bath does not have any mechanical stability, since no precipitation has occurred yet. For flat membranes the supporting materials enables transport to the second bath. In spinning the situation is more complicated, due to the absence of a support. A possible solution is a two-layer system, by which the first nonsolvent is on top of the second one. When such a set-up is chosen, the following aspects are of importance:

(1) the density of the first nonsolvent should be lower than that of the second nonsolvent; (2) diffusion of nonsolvent from the second bath into the first one should still allow delayed demixing in the first bath;

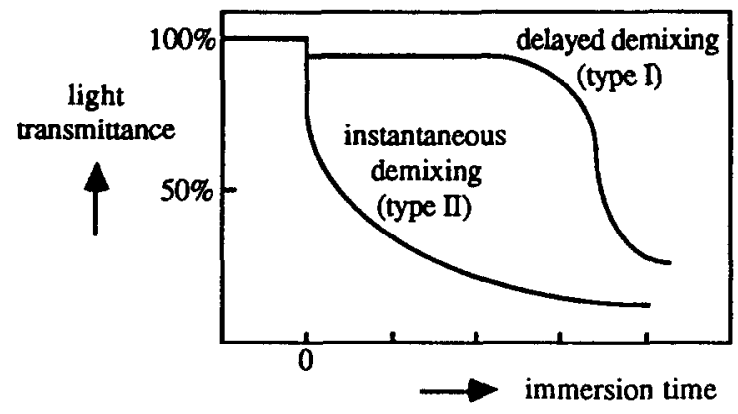

Fig. 2. Light transmittance as a function of immersion time.
(3) considerable amounts of the first nonsolvent in the second bath should still give instantaneous demixing in this second bath.

When two nonsolvents with considerable miscibility are preferred (as may result from the desired demixing properties indicated by light transmission measurements), two separate nonsolvent baths have to be used. In the experimental section the practical aspects of hollow fibre spinning according to the dual-bath method are discussed in more detail.

\section{Experimental}

For the preparation of flat films and hollow fibres a polymer solution was used consisting of $35 \%(\mathrm{w} / \mathrm{w})$ polyethersulfone (PES, VICTREX $^{\circledast}$ from ICI) and $10 \%(w / w)$ glycerol in $\mathrm{N}$-methylpyrrolidone (NMP). NMP (synthesis grade) and glycerol (water-free) were purchased from Merck and used without further treatment. PES was dried for at least $3 \mathrm{hr}$ at $150^{\circ} \mathrm{C}$ prior to use.

Delay times for demixing were determined for various combinations of NMP/glycerol and alcohols (see Table 1, below, for the alcohols used). All alcohols were of synthesis grade. To investigate the possible effect of convective flow in polymer solution and nonsolvent bath on delay times several experiments were performed with the polymer films upside-down in the nonsolvent bath. No differences could be detected.

Flat membranes were cast by hand on a glass plate and had initial thickness of $0.20 \mathrm{~mm}$. Immediately after casting, the films were immersed in the first nonsolvent bath, and after a certain residence time transferred to the second nonsolvent bath. The time in the second bath was at least $30 \mathrm{~min}$. After one night in ethanol (to remove residual NMP and alcohol) the films were dried at $80^{\circ} \mathrm{C}$.

As mentioned before, the dual-bath spinning method may be performed in two different ways, depending on the type of liquids used in both nonsolvent baths. Figure 3 shows the set-up 
TABLE 1

Delay times for a solution of $35 \%$ (w/w) PES and $10 \%$ glycerol in NMP, immersed in various nonsolvents (NS), as well as viscosities and estimated diffusion coefficients (at $25^{\circ} \mathrm{C}$ )

\begin{tabular}{|c|c|c|c|c|c|}
\hline Nonsolvent & Molecular formula & $\begin{array}{l}\text { Viscosity } \\
\text { (cPoise) }\end{array}$ & $\begin{array}{l}\text { Delay time } \\
\text { (sec) }\end{array}$ & $\begin{array}{l}D^{\mathrm{o}} \mathrm{NMP} / \mathrm{Ns}^{\mathrm{a}} \\
\left(10^{-6} \mathrm{~cm}^{2} / \mathrm{sec}\right)\end{array}$ & $\begin{array}{l}D^{\mathrm{O}} \mathrm{NS} / \mathrm{NMP}^{\mathrm{a}} \\
\left(10^{-6} \mathrm{~cm}^{2} / \mathrm{sec}\right)\end{array}$ \\
\hline Water & $\mathrm{H}_{2} \mathrm{O}$ & 1.00 & 0 & 8.7 & 18.0 \\
\hline Methanol & $\mathrm{CH}_{3}-\mathrm{OH}$ & 0.60 & 0 & 16.2 & 12.6 \\
\hline Ethanol & $\mathrm{CH}_{3} \mathrm{CH}_{2}-\mathrm{OH}$ & 1.22 & 0 & 8.5 & 10.5 \\
\hline 2-Propanol & $\mathrm{CH}_{3}-\mathrm{CHOH}-\mathrm{CH}_{3}$ & 2.40 & 200 & 4.7 & 9.6 \\
\hline 1-Butanol & $\mathrm{CH}_{3}-\left(\mathrm{CH}_{2}\right)_{3}-\mathrm{OH}$ & 2.95 & 220 & 4.2 & 8.7 \\
\hline 1-Pentanol & $\mathrm{CH}_{3}-\left(\mathrm{CH}_{2}\right)_{4}-\mathrm{OH}$ & 3.31 & 440 & 3.9 & 8.0 \\
\hline $\begin{array}{l}\text { Id., sat'd with } \\
\text { water }\end{array}$ & & & 0 & & \\
\hline 1-Octanol & $\mathrm{CH}_{3}-\left(\mathrm{CH}_{2}\right)_{7}-\mathrm{OH}$ & 8.93 & 600 & 1.7 & 6.6 \\
\hline $\begin{array}{l}\text { Id., sat'd with } \\
\text { water }\end{array}$ & & & 0 & & \\
\hline Cyclohexanol & $\mathrm{C}_{6} \mathrm{H}_{11}-\mathrm{OH}$ & 49.8 & 600 & 0.3 & 7.9 \\
\hline Glycerol & $\mathrm{CH}_{2} \mathrm{OH}-\mathrm{CHOH}-\mathrm{CH}_{2} \mathrm{OH}$ & 945 & 1200 & 0.02 & 9.0 \\
\hline 1,4-Butanediol & $\mathrm{CH}_{2} \mathrm{OH}-\left(\mathrm{CH}_{2}\right)_{2}-\mathrm{CH}_{2} \mathrm{OH}$ & 70 & 0 & $\approx 0.2$ & $\approx 8.4$ \\
\hline Glycol & $\mathrm{CH}_{2} \mathrm{OH}-\mathrm{CH}_{2} \mathrm{OH}$ & 17.4 & 0 & 0.7 & 10.6 \\
\hline
\end{tabular}

${ }^{\mathrm{a}} D^{\mathrm{o}} \mathrm{NMP} / \mathrm{NS}$ and $D^{\mathrm{o}} \mathrm{NS} / \mathrm{NMP}$ are the calculated diffusion coefficients for NMP in almost pure nonsolvent (infinite dilution of NMP in NS) and nonsolvent in almost pure NMP, respectively (see Appendix). Viscosity data are obtained from [21] and [22].

used for two miscible nonsolvents (e.g. glycerol and water). Here, the first bath consisted of a glass vessel with a hole in the bottom, which was slightly larger than the fibre diameter. Three different vessels were used, with heights of 13,27 and $65 \mathrm{~mm}$, respectively.

The other configuration used was a two-layer system (for non-miscible liquids, e.g. pentanol and water). For such situations the vessel just below the spinneret (see Fig. 3) was removed, and a layer of the first nonsolvent was brought on top of the second nonsolvent. The maximum height used for the first liquid was 300 $\mathrm{mm}$, while the total length of the coagulation bath was approximately $1700 \mathrm{~mm}$. Both the nonsolvent bath and the rinsing bath were temperature controlled. The fibres were spun at a rate of $4-6 \mathrm{~m} / \mathrm{min}$. In all cases a tube-in-orifice spinneret was used with an orifice of $0.6 \mathrm{~mm}$ and an outer capillary diameter of $0.2 \mathrm{~mm}$. Water of ambient temperature was used as a bore fluid. After spinning the fibres were cut into lengths of about $30 \mathrm{~cm}$, rinsed with tap water for 5-20 hr and air-dried at ambient temperature and a relative humidity of $50 \%$. In several cases water and residual NMP in the fibres were replaced by ethanol and subsequently by $\mathrm{n}$-hexane before air-drying. This was done by putting the fibres in ethanol for several hours (3-20 hr), immediately after rinsing, followed by immersion in n-hexane for another 3-20 hr.

For testing purposes small test samples of 10 15 fibres were made. From each type of fibre at least two samples were prepared. These were mounted in a stainless steel module and tested with a feed gas of 20-25 vol.\% of $\mathrm{CO}_{2}$ in $\mathrm{CH}_{4}$ at pressures of 4-8 atm and a temperature of $23^{\circ} \mathrm{C}$. The feed flow rate was large compared to that of the permeate. The bore side of the fibres was evacuated to a pressure less than $10^{-3}$ atm. The conditioning time before each measurement was at least $90 \mathrm{~min}$. 


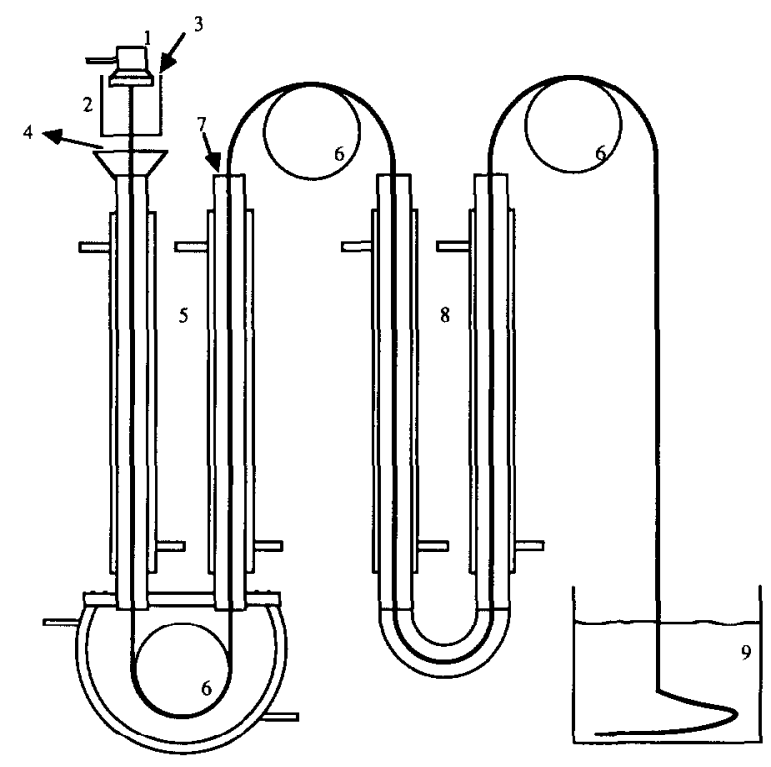

Fig. 3. Spinning of hollow fibres according to the dual-bath procedure. (1) spinneret, (2) first nonsolvent bath, (3) inlet first nonsolvent, (4) outlet second nonsolvent, (5) second nonsolvent bath, (6) guiding rolls, (7) inlet second nonsolvent, (8) rinsing bath (water), (9) collecting bath (water).

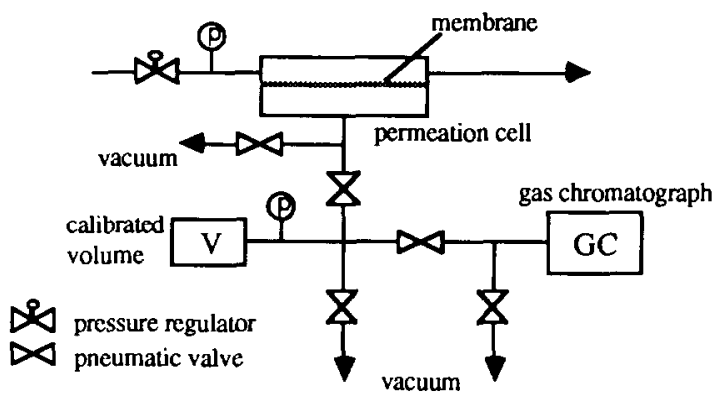

Fig. 4. Gas permeability measurement set-up.

The permeability test set-up is given in Fig. 4. The gas flux through the membranes was determined by measuring the pressure increase ( 15 or $25 \mathrm{mmHg}$ ) in a calibrated volume for a certain period of time, using an MKS Baratron capacitance pressure transducer. The composition of both feed and permeate gas was determined with a gas chromatograph.

For structure investigations the fibres were prepared by cryogenic breaking in liquid nitrogen, followed by sputtering of a thin layer of gold. Cross-sections of the fibres were examined with a JEOL 35 CF scanning electron microscope.

\section{Results and discussion}

Previous work in our laboratory had shown that a polymer solution containing $35 \%(\mathrm{w} / \mathrm{w})$ PES and $10 \%(\mathrm{w} / \mathrm{w})$ glycerol in NMP gives the desired finely porous membrane structures with no macrovoids when coagulated in water. Therefore, this composition was used in the dual-bath procedure as well. For these solutions the delay times were determined in several nonsolvents. Next, flat asymmetric films were made by contacting a thin film of the solution with two nonsolvent baths in succession. By varying the immersion time in the first bath the effect on gas flux and selectivity was investigated. Furthermore, spinning experiments were performed in two different ways, as described in the experimental section. The results of the experiments will be discussed in this section.

\section{Delay times for demixing}

In Table 1 results are given for the delay time measurements. Furthermore, viscosities of the various nonsolvents are given, together with the calculated binary diffusion coefficients at infinite dilution of NMP in different nonsolvents, as well as those of the nonsolvents in NMP. The method used for estimation of the diffusion coefficients (from Reid et al. [20]) is given in an appendix.

As can be seen from Table 1 nonsolvents with three or more carbon atoms give a considerable delay time for demixing and might be suitable as a first nonsolvent. Except for 1,4-butanediol and glycol, the delay time increases with the 
viscosity of the alcohol used. The estimated binary diffusion coefficients show that the differences for penetration of alcohol in NMP are only small (diffusion coefficients $D^{\circ}{ }_{\mathrm{NS} / \mathrm{NMP}}$ of $6.6-12.6 \times 10^{-6} \mathrm{~cm}^{2} / \mathrm{sec}$ are obtained for all alcohols). Moreover, it is believed that the effect of $D^{\circ}$ NS/NMP on demixing is insignificant because of the high viscosity of the polymer/NMP solution. The second diffusion coefficient $D^{\circ}$ NMP/NS is much more important, because the rate of solvent/nonsolvent exchange is mainly determined by the minimum value of the diffusion coefficient, $D^{\circ}$ NMP/NS [13]. When the rate of exchange of solvent and nonsolvent is lower (because of a lower diffusion coefficient) it takes a considerably longer period of time before enough solvent is depleted from the polymer solution to give demixing.

The last two liquids mentioned in Table 1 (1,4-butanediol and glycol) have viscosities and $D^{0}{ }_{\text {NMP/NS }}$ values comparable to those of cyclohexanol. They did not show any delay time for demixing, however, This unexpected behaviour may be caused by a better thermodynamic interaction of 1,4-butanediol and glycol with NMP, or by the presence of water in these liquids. This requires experimental verification.

Table 1 shows that potential nonsolvents for the second bath are water, methanol, and ethanol. Furthermore, water saturated alcohols (e.g. 1-pentanol and 1-octanol) might also be used in the second nonsolvent bath.

\section{Flat membranes}

Flat membranes have been prepared for two different reasons. In the first place it had to be demonstrated that a dual-bath coagulation system would indeed lead to asymmetric membranes with high selectivity. Furthermore, possible nonsolvent combinations for a spinning procedure could be identified by making films.

It should be noted that it was difficult to make flat membranes by hand in a reproducible way, especially with two nonsolvent baths. Within one series of experiments the results often were very scattered. Although the immersion time in the first nonsolvent bath was varied over a considerable period of time (between 0 and $30 \mathrm{sec}$ ), it was impossible to prove the relation between immersion time and flux quantitatively. This might be caused by the following factors:

- inhomogeneities in the cast films;

- variations in the residence time in the first bath;

- non-reproducible way of bringing a film from the first to the second nonsolvent bath;

- contamination of both nonsolvent baths (approximately 10 membranes were prepared before replacing each of the liquids ).

Since the major objective was to spin hollow fibres according to the dual-bath method, it was not tried to improve or optimize the process for making flat membranes (for example, by using a casting machine).

Table 2 shows that membranes with high gas selectivities can be prepared according to the dual-bath procedure, and that the gas flux strongly depends upon the combination of nonsolvents used. Using 1-pentanol in combination with water in the second bath the highest flux is obtained. This high flux is most likely caused by the fact that residual pentanol is rapidly removed from the film surface, due to the low density of pentanol and the poor miscibility of both liquids. The relatively short contact time with the first nonsolvent thus results in a thin top layer and therefore in a good flux. With glycerol as the first nonsolvent it is much more difficult for water to reach the surface of the polymer film, since the highly viscous glycerol forms a rather impermeable film around the polymer solution. This causes the type I demixing process to proceed significantly longer, resulting in a thicker top layer and a lower flux. When ethanol is used instead of water as the second nonsolvent, a much lower flux is obtained. Possibly, the transition from delayed 
TABLE 2

Gas permeation properties of various flat membranes, prepared according to the dual-bath procedure

\begin{tabular}{|c|c|c|c|c|}
\hline Membrane & $\begin{array}{l}\text { Nonsolvent-1 } \\
\text { (density) }^{\mathbf{b}}\end{array}$ & $\begin{array}{l}\text { Nonsolvent-2 } \\
\text { (density) }^{\mathrm{b}}\end{array}$ & $\begin{array}{l}\text { Gas flux } \\
(P / l)_{\mathrm{CO}_{2}}\end{array}$ & $\begin{array}{l}\text { Selectivity } \\
\alpha\left(\mathrm{CO}_{2} / \mathrm{CH}_{4}\right)\end{array}$ \\
\hline 1 & $\begin{array}{l}\text { Water } \\
(1.00)\end{array}$ & $\begin{array}{l}\text { Water } \\
(1.00)\end{array}$ & 8.2 & 4 \\
\hline 2 & $\begin{array}{l}\text { 1-Pentanol } \\
(0.82)\end{array}$ & $\begin{array}{l}\text { Water } \\
(1.00)\end{array}$ & 5.0 & 55 \\
\hline 3 & $\begin{array}{l}\text { Glycerol } \\
(1.26)\end{array}$ & $\begin{array}{l}\text { Water } \\
(1.00)\end{array}$ & 3.7 & 56 \\
\hline 4 & $\begin{array}{l}\text { 1-Pentanol } \\
(0.82)\end{array}$ & $\begin{array}{l}\text { Ethanol } \\
(0.79)\end{array}$ & 1.9 & 56 \\
\hline
\end{tabular}

${ }^{\mathrm{a}} 10^{-6} \mathrm{~cm}^{3} / \mathrm{cm}^{2}-\mathrm{sec}-\mathrm{cmHg}$.

$\mathrm{b} / \mathrm{cm}^{3}$.

Polymer solution: $35 \%(w / w)$ PES and $10 \%$ glycerol in NMP; $T=40^{\circ} \mathrm{C}$. Immersion times: 1st bath: 5 sec; 2 nd bath: $>30$ $\min$.

demixing to instantaneous demixing is not fast enough (according to Swinyard and Barrie [23] ethanol is a significantly weaker nonsolvent for PES than water is). This may give either a thick top layer or a poor interconnection of pores in the sub layer; both result in lower membrane permeability.

\section{Hollow fibres}

\section{Influence of the coagulation system,}

For the preparation of asymmetric hollow fibres two different methods were used: (a) two layers of contacting nonsolvents and (b) two separate nonsolvent baths. Table 3 gives some results for both systems.

As can be seen a two layer system with 1pentanol in contact with water may result in good selectivities. Selectivity almost completely disappears, however, after longer spinning runs (about $2 \mathrm{hr}$ ). This is believed to be caused by penetration of water in the upper (pentanol) layer. As shown already in Table 1 saturation of the alcohol with water gives instantaneous demixing. Even though the solubility of water and 1-pentanol is only $9.2 \%(\mathrm{w} /$ w) at $20^{\circ} \mathrm{C}[20]$, this value corresponds to

\section{TABLE 3}

Gas flux and selectivity of PES hollow fibre membranes, prepared by two coagulation systems, with 1-pentanol as the first nonsolvent and water as the second nonsolvent

\begin{tabular}{lllll}
\hline $\begin{array}{l}\text { Fibre } \\
\text { First } \\
\text { nonsolvent }\end{array}$ & System & $\begin{array}{l}\text { Gas flux }^{\mathrm{a}} \\
(P / l)_{\mathrm{CO}_{2}}\end{array}$ & $\begin{array}{l}\text { Selectivity } \\
\alpha\left(\mathrm{CO}_{2} / \mathrm{CH}_{4}\right)\end{array}$ \\
\hline 1 & Water & - & 9,2 & 3 \\
$2 \mathrm{a}$ & 1-Pentanol & 2 Layers & 2.0 & 47 \\
2b & Same & Same & 3.7 & 46 \\
2c & Same & Same & 11 & 1 \\
3 & 1-Pentanol & 2 Baths & 8.0 & 3 \\
\hline
\end{tabular}

${ }^{\mathrm{a}} 10^{-6} \mathrm{~cm}^{3} / \mathrm{cm}^{2}$-sec-cmHg.

${ }^{b}$ Height of the 1-pentanol layer: $270-350 \mathrm{~mm}$.

${ }^{c}$ Height of the 1st bath: $27 \mathrm{~mm}$.

$2 a, 2 b$ and $2 c$ were collected after $\pm 30,60$ and 120 min of spinning time, resp.

Spinning solution: $35 \%(w / w)$ PES and $10 \%$ glycerol in NMP $\left(T=42^{\circ} \mathrm{C}\right)$. Spinning rate: $4 \mathrm{~m} / \mathrm{min}$. Airgap length: $50 \mathrm{~mm}$ (air, temperature: $20^{\circ} \mathrm{C}$; relative humidity $50 \%$ ). Temperature 1st and 2nd nonsolvent: $20^{\circ} \mathrm{C}$.

about $33 \mathrm{~mol} \%$. The activity of the water present in the alcohol layer after a certain time might be sufficiently high to prevent delayed demixing in the upper layer. Thus, a dense top layer is not formed anymore. Another reason for the loss of selectivity might be accumulation of NMP in the pentanol layer. A substan- 
tial amount of NMP in 1-pentanol reduces the driving force for NMP out of the nascent fibre, thus hindering a polymer concentration buildup at the interface.

With 1-pentanol in a system with two separate baths, as shown in Table 3, there is no improvement in selectivity (compared to the values obtained with only water as the nonsolvent), while the flux is somewhat lower. This low selectivity is most likely caused by an insufficient residence time in the first bath. With a spinning rate of $4 \mathrm{~m} / \mathrm{min}$ and a height of the glass vessel of $27 \mathrm{~mm}$ the residence time was only $0.4 \mathrm{sec}$. For the two layer system (membranes 2 in Table 3 ) this time was about $4.5 \mathrm{sec}$.

All spinning experiments described hereafter were performed with two separate nonsolvent baths.

\section{Glycerol as the first nonsolvent}

Because the preparation of flat membranes using glycerol in the first nonsolvent bath showed very promising results, spinning experiments were done with this nonsolvent in the first bath and water in the second one (see Table 4).

Using glycerol as the first nonsolvent fibres with very good selectivities are obtained, al-

\section{TABLE 4}

Gas permeation properties of hollow fibre membranes, prepared according to the dual-bath procedure, with glycerol as the first nonsolvent and water as the sccond nonsolvent

\begin{tabular}{lllll}
\hline Fibre & $\begin{array}{l}\text { First } \\
\text { nonsol- } \\
\text { vent }\end{array}$ & $\begin{array}{l}\text { Immersion time } \\
(\mathrm{sec})\end{array}$ & $\begin{array}{l}\text { Gas flux } \\
(P / l)_{\mathrm{CO}_{2}}\end{array}$ & $\begin{array}{l}\text { Selectivity } \\
\alpha\left(\mathrm{CO}_{2} / \mathrm{CH}_{4}\right)\end{array}$ \\
\hline 1 & Water & - & 10 & 2 \\
2 & Glycerol 0.17 & 2.5 & 53 \\
\hline
\end{tabular}

${ }^{a} 10^{-6} \mathrm{~cm}^{3} / \mathrm{cm}^{2}$-sec-cmHg.

Length of the first bath: $13 \mathrm{~mm}$. Spinning rate: $4.7 \mathrm{~m} / \mathrm{min}$. Second bath: demineralized water $\left(30^{\circ} \mathrm{C}\right)$; immersion time $>15$ sec. though the flux is fairly low. During spinning it was observed that glycerol formed a rather thick film around the fibre, which was only disturbed by the water near the lowest point in the second coagulation bath. Due to the large viscosity and density of glycerol compared to that of water (see Tables 1 and 2, respectively), the penetration of water is very slow. The calculated residence time of $0.17 \mathrm{sec}$ in the first bath therefore is not accurate and maybe this value should be multiplied by a factor of at least 5 or 6 (estimated from the phenomena observed during spinning). The result is a thick top layer with low gas permeability.

From permeation measurements in our laboratory on homogeneous PES films a permeability for $\mathrm{CO}_{2}$ of 4-5 barrer was obtained (1 barrer $=10^{-10} \mathrm{~cm}^{3}$ (STP) $-\mathrm{cm} / \mathrm{cm}^{2}$-sec-cmHg). When it is assumed that the top layer fully determines the transport, a top layer thickness of 1.6-2.0 $\mu \mathrm{m}$ can be calculated for the 'glycerol fibres' in Table 4. Removal of the top layer of these fibres in an oxygen plasma showed that the thickness of the top layer is about $2 \mu \mathrm{m}$ and that it is responsible for more than $98 \%$ of the total membrane resistance [24]. These results are in good agreement with the data shown in Table 4.

The reproducibility of this dual-bath spinning method, using glycerol as the first nonsolvent and water as the second one was very good. The variations in both flux and selectivity were less than $10 \%$.

The structure of a glycerol/water coagulated fibre is shown in Fig. 5 . As can be seen very large macrovoids are present, which start at the inside and extend over almost the total wall thickness. This means that a considerable penetration of the demixing front from the inside has taken place before demixing from the outside starts. As stated before in the section on membrane formation, delayed demixing is possible as long as the polymer solution can be treated as semi-infinite. However, when coag- 


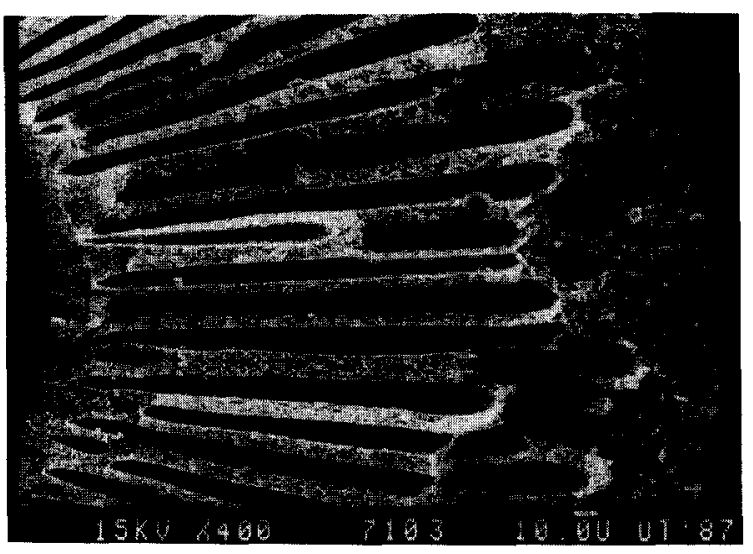

Fig. 5. Cross-section of a hollow fibre, coagulated in glyc$\mathrm{erol} /$ water.

ulation from the inside disturbs diffusion in the original polymer solution, the conditions for delayed demixing on the outside may no longer be fulfilled and phase separation can take place. Thus, the bore liquid might have a significant influence on the thickness of the outer top layer. Reducing the 'demixing power' of the bore liquid (for example, by addition of solvent) or even by using gas in the bore should minimize the effect on the structure formation from the outside.

The presence of large macrovoids when contacting the nascent fibre with glycerol (or pentanol) prior to the immersion in water clearly indicates the influence of the first nonsolvent on the membrane formation process. As mentioned before, direct immersion in water resulted in essentially macrovoid-free fibres. In a related publication [25] it is reasoned that a high ratio of solvent to nonsolvent in the polymer solution during the membrane formation promotes macrovoid formation. By delaying the inflow of nonsolvent solvent/nonsolvent will remain relatively high, promoting formation and growth of macrovoids (see also [26]).

Despite the large macrovoids the mechanical stability of the fibres was acceptably high: pressures up to 50 bars could be held without im- plosion. It is believed that the regular structure of the macrovoids and the relatively thick top layer on the outside are responsible for this good mechanical stability.

\section{Effect of the drying procedure}

From literature it is known that direct drying of membranes can lead to changes in structure and properties, caused by large capillary forces present during this drying process [27]. Especially in pores with relatively small radii these forces can be so high that the membrane structure is altered. Such pores are found just beneath the top layer of an asymmetric membrane, and drying can lead to a considerable densification of the structure in this part. As a result an increased permeation resistance, or even a distortion of the whole membrane is possible. For cellulose acetate these phenomena are often observed (as an example, see Vasarhelyi et al. [28]). An indication that the same complications may happen with aromatic polymers like PES, is the observation that totally curled membranes are obtained when PES films, prepared by the dual-bath coagulation method (with the combination glycerol/water), were air-dried immediately after washing with water.

As shown before the dual-bath process with glycerol/water as the coagulation system results in fibres with a rather thick top layer. To investigate whether the phenomena mentioned above influenced this thickness PES fibres were dried in two different ways. Besides the normal procedure (drying in ambient air of a moderate humidity) a liquid exchange method was employed [29]. Here, water in the membrane is not removed by evaporation in air, but gradually replaced by less polar components with lower surface tension, which are at least partially miscible with the previous component. Often the sequence water-alkanol-alkane-air is used. By this treatment the small pores present under the top layer of the membrane will not collapse so easily and the effective separat- 
ing layer may become thinner, resulting in a higher flux.

As the data in Table 5 show, controlled removal of water results in higher gas flux, but slightly lower selectivity. One explanation for this lower selectivity might be that the top layer still contains some defects (tiny pores) after spinning, which are contracted upon drying in air. A second explanation could be the presence of residual solvent (NMP) in the fibres after spinning. When these fibres are dried in air (without sufficient extraction of solvent), water will be removed first, due to its higher surface tension (see Table 6) and higher volatility. Remaining solvent in pores in and just below the outer top layer may lead to plasticization of the polymer. Thus, a densification of the top layer is possible upon drying. When ethanol and/or $\mathrm{n}$-hexane are used in the drying procedure,

\section{TABLE 5}

Gas permeation properties of hollow fibre membranes, dried in two different ways

\begin{tabular}{llll}
\hline Fibre & Drying method & $\begin{array}{l}\text { Gas flux } \\
(P / l)_{\mathrm{CO}_{2}}\end{array}$ & $\begin{array}{l}\text { Selectivity } \\
\alpha\left(\mathrm{CO}_{2} / \mathrm{CO}_{4}\right)\end{array}$ \\
\hline 1 & Air & 2.5 & 53 \\
2 & EtOH/hexane/air & 7.1 & 41 \\
3 & Air & 2.3 & 46 \\
4 & EtOH/hexane/air & 6.3 & 32 \\
\hline
\end{tabular}

${ }^{a} 10^{-6} \mathrm{~cm}^{3} / \mathrm{cm}^{2}$-sec-cmHg.

$1 / 2$ and $3 / 4$ were prepared under slightly different spinning conditions.

\section{TABLE 6}

Surface tensions of some liquids at $25^{\circ} \mathrm{C}$ (from [21])

\begin{tabular}{ll}
\hline Liquid & $\begin{array}{l}\text { Surface tension } \sigma \\
(\text { dyne/cm) }\end{array}$ \\
\hline Water & 72.5 \\
NMP & 40.7 \\
Ethanol & 22.7 \\
n-Hexane & 17.9 \\
\hline
\end{tabular}

water as well as NMP will be replaced and no plasticization can occur.

From the electron micrographs in Fig. 6 it can be clearly seen that a considerably thicker top layer is obtained when the fibres are only air-dried. Using ethanol and n-hexane in the drying procedure results in a thin top layer (thickness less than $1 \mu \mathrm{m}$ ) and small pores just under the top layer (pore radii in the order of $0.1 \mu \mathrm{m})$.

From the permeation data in Tables 2 and 3 it can be seen that flat films have a significantly higher $\mathrm{CO}_{2}$-flux than the fibres, when 1-pentanol is used in the first nonsolvent bath (compare membrane 2 in Table 2 with membranes $2 a$ and $2 b$ in Table 3 ). The differences may be

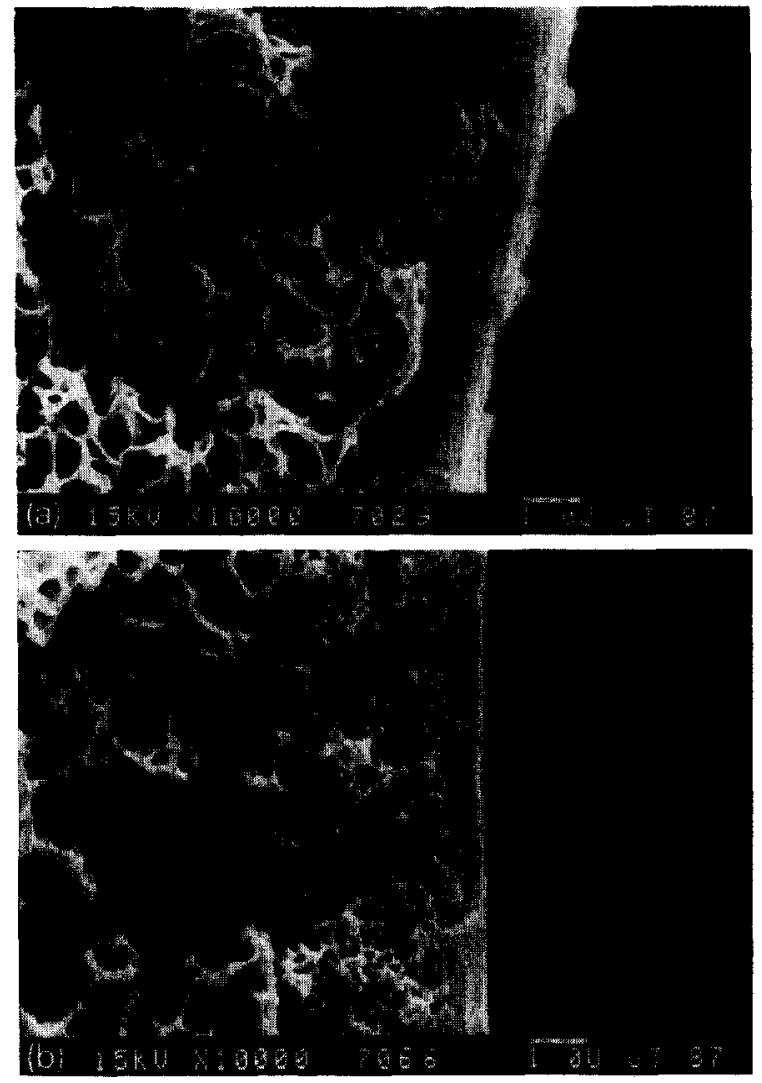

Fig. 6. Cross-section of the outer top layer of hollow fibre membranes, dried by evaporation in air (a) and dried by liquid exchange, followed by evaporation (b). 
caused by the drying method, since these hollow fibres were immediately air-dried after washing with water, while the rinsed films were treated with ethanol before air-drying.

\section{Conclusions}

It has been demonstrated that selective asymmetric gas separation membranes can be prepared by using two successive nonsolvent baths during precipitation. No volatile solvents are needed in the spinning process, nor an additional 'repair' coating. Both flat films and hollow fibres were obtained with selectivities $\alpha\left(\mathrm{CO}_{2} / \mathrm{CH}_{4}\right)$ of $50-55$, which is comparable to the intrinsic value of polyethersulfone (PES), the polymer used in all experiments.

Some initial dual-bath spinning experiments have been performed with other polymers (i.e. polyetherimide and polyimides), to demonstrate a more general applicability of the method. In various cases intrinsic selectivities were obtained, and we hope to report on these data in future publications.

Next step in the development of this dualbath spinning process should be improvement of gas flux, while maintaining the high selectivity. Controlled washing and drying has shown to result in higher fluxes, but it should be possible to optimize the spinning process to lower the membrane thickness significantly below 1 $\mu \mathrm{m}$. Shorter residence time in the first bath is a very important issue, which can be achieved, for example, by increasing the spinning rate. This increased rate will also help to make the process more attractive for large scale production. These aspects, and other process parameters (like technical lay-out of a dual-bath spinning line) are currently investigated.

\section{Acknowledgement}

The work described in this paper was financially supported by the Dutch Ministry of Economic Affairs and AKZO NV.

\section{References}

1 S. Loeb and S. Soerirajan, Sea water demineralization by means of an osmotic membrane, Adv. Chem. Ser., 38 (1962) 117.

2 J. Bouchilloux, A. Fabre and A. Fauvre, Anisotropic organosilicon polymer membrane, U.S. Patent 3,754,375 (1973).

3 S.G. Kimura, Preparation of asymmetric polymer membranes, U.S. Patent 3,709,774 (1973).

4 K.-V. Peinemann and I. Pinnau, Verfahren zur Her stellung und Erhöhung der Selektivität einer integralasymmetrischen Membran, German Patent DE 3525235 (1986).

5 K.-V. Peinemann, Verfahren zur Herstellung einer integralasymmetrischen Membran, German Patent DE 3420373 (1984).

6 I. Pinnau and W.J. Koros, Defect-free ultrahigh flux asymmetric membranes, U.S. Patent 4,902,422 (1990).

7 J.M.S. Henis and M.K. Tripodi, Composite hollow fiber membranes for gas separation: The resistance model approach, J. Membrane Sci., 8 (1981) 233.

8 M.K. Murphy, E.R. Beaver and A.W. Rice, Posttreatment of asymmetric membranes for gas application, AIChE Sym. Ser. No. 272, Vol. 85, 1989, 34-40.

9 I. Pinnau, J.G. Wijmans, I. Blume, T. Kuroda and K.V. Peinemann, Gas permeation through composite membranes, J. Membrane Sci., 37 (1988) 81-88.

10 K.A. Lundy and I. Cabasso, Analysis and construction of multilayer composite membranes for the separation of gas mixtures, Ind. Eng. Chem. Res., 28 (1989) 742-756.

11 S.C. Williams, B. Bikson, J.K. Nelson and R.D. Burchesky, Method for preparing composite membranes for enhanced gas separation, U.S. Patent 4,840,819 (1989).

12 P.S. Puri, Process for making highly permeable coated composite hollow fiber membranes, U.S. Patent 4,756,932 (1988).

13 A.J. Reuvers and C.A. Smolders, Formation of membranes by means of immersion precipitation. Part II. The mechanism of formation of membranes prepared from the system CA/acetone/water, J. Membrane Sci., 34 (1987) 67.

14 A.J. Reuvers, J.W.A. v.d. Berg and C.A. Smolders, Formation of membranes by means of immersion precipitation. Part I. A model to describe mass transfer during immersion precipitation, J. Membrane Sci., 34 (1987) 45.

15 A.J. Reuvers, Membrane formation - Diffusion induced demixing processes in ternary polymeric systems, Ph.D. Thesis, University of Twente, Enschede, The Netherlands, 1987, Chap. 7. 
16 H. Strathmann, Trennung von molekularen Mischungen mit Hilfe synthetischer Membranen, Steinkopff, Darmstadt, 1979.

17 P.J.Dunlop, Frictional coefficients for binary and ternary isothermal diffusion, J. Phys. Chem., 68(1) (1964) 26.

18 J.A. Ronner (University of Twente), to be published.

19 A.J. Reuvers, private communication, University of Twente, December 1986.

20 R.C. Reid, J.M. Prausnitz and B.E. Poling, The properties of gases and liquids, in: B. Sun, G.H. Fleck (Eds. ), McGraw-Hill Book Company, New York, NY, 1987.

21 E.W. Flick (Ed.), Industrial Solvents Handbook, 3rd edn., Noyes Data Corporation, Park Ridge, NJ, 1985.

22 Handbook of Chemistry and Physics, R.C. Weast (Ed.), 57th edn., CRC Press, Inc., Boca Raton, FL, 1976-77.

23 B.T. Swinyard and J.A. Barrie, Phase separation in non-solvent/dimethylformamide/polyethersulphone and non-solvent/dimethylformamide/polysulphone systems, Brit. Polym. J., 20 (1988) 317-321.

24 J.A. van 't Hof, Wet spinning of asymmetric hollow fibre membranes for gas separation, Ph.D. Thesis, University of Twenty, Enschede, The Netherlands, 1988, Chap. 6.

25 J.A. van 't Hof, Wet spinning of asymmetric hollow fibre membranes for gas separation, Ph.D. Thesis, University of Twenty, Enschede, The Netherlands, 1988, Chap. 5.

26 A.J. Reuvers, Membrane formation - Diffusion induced demixing processes in ternary polymeric systems, Ph.D. Thesis, University of Twente, Enschede, The Netherlands, 1987, Appendix.

27 R.E. Kesting, Concerning the microstructure of dryRO membranes, J. Appl. Polym. Sci., 17 (1973) 1771.

28 K. Vasarhelyi, J.A. Ronner, M.H.V. Mulder and C.A. Smolders, Development of wet-dry reversible membranes with high performance from cellulose acetate and cellulose triacetate blends, Desalination, 61 (1987) 211.

29 MacDonald, Method for drying water-wet membranes, U.S. Patent 3,842,515 (1974).

\section{Appendix}

\section{Estimation of binary diffusion coefficient}

By Reid et al. [20] estimation methods are given for the calculation of the diffusion coef- ficient of liquid $A$ in pure liquid $B$ (infinite dilution of $\mathrm{A}$ in $\mathrm{B}$ ) $D^{\circ}{ }_{\mathrm{AB}}$. Two methods were used to calculate the values in Table 1:

$$
\begin{aligned}
D_{\mathrm{AB}}^{\mathrm{o}}= & 8.93 \times 10^{-8}\left(V_{\mathrm{B}}^{0.267} / V_{\mathrm{A}}^{0.433}\right) \\
& \times\left(T / \eta_{\mathrm{B}}\right)\left(\sigma_{\mathrm{B}} / \sigma_{\mathrm{A}}\right)^{0.15}
\end{aligned}
$$

(Tyn-Calus)

$$
\begin{aligned}
D_{\mathrm{AB}}^{\circ}= & 1.55 \times 10^{-8}\left(V_{\mathrm{B}}^{0.27} / V_{\mathrm{A}}^{0.42}\right) \\
& \times\left(T^{1.29} / \eta_{\mathrm{B}}^{0.92}\right)\left(\sigma_{\mathrm{B}}^{0.125} / \sigma_{\mathrm{A}}{ }^{0.105}\right)
\end{aligned}
$$

(Hayduk-Minhas)

With: $D^{\circ}{ }_{\mathrm{AB}} \quad$ diffusion coefficient of solute $\mathrm{A}$ at very low concentrations in solvent $\mathrm{B}\left(\mathrm{cm}^{2} / \mathrm{sec}\right)$

$V_{\mathrm{A}}, V_{\mathrm{B}}$ molar volume of solute $\mathrm{A}$ and solvent $B$ at normal boiling temperature, respectively $\left(\mathrm{cm}^{3} /\right.$ mol)

$T \quad$ temperature (K)

$\eta_{\mathrm{B}} \quad$ viscosity of solvent $\mathrm{B}$ (cPoise)

$\sigma_{\mathrm{A}}, \sigma_{\mathrm{B}}$ surface tension of $\mathrm{A}$ and $\mathrm{B}$, respectively (dyne/cm)

\section{Example}

For water and NMP the calculated diffusion coefficients at $25^{\circ} \mathrm{C}$ are given below. The physical properties of both liquids were obtained from [22].

$D_{\text {NMP/water }}^{\circ}=8.93 \times 10^{-8}\left(18.0^{0.267} / 96.5^{0.433}\right) \times$ $(298 / 1.0)(72.5 / 40.7)^{0.15}=8.7 \times 10^{-6}\left(\mathrm{~cm}^{2} /\right.$ $\mathrm{sec})$ (Tyn-Calus)

$D_{\mathrm{NMP} / \text { water }}^{\mathrm{o}}=1.55 \times 10^{-8}\left(18.0^{0.27} / 96.5^{0.42}\right)$ $\left(298^{1.29} / 1.0^{0.29}\right)$ $\left(72.5^{0.125} / 40.7^{0.105}\right)=$ $8.9 \times 10^{-6}\left(\mathrm{~cm}^{2} / \mathrm{sec}\right)$ (Hayduk-Minhas) $D^{\mathrm{o}}{ }_{\text {water } / \mathrm{NMP}}=8.93 \times 10^{-8}\left(96.5^{0.267} / 18.0^{0.433}\right)$ $(298 / 1.65)(40.7 / 72.5)^{0.15}=14.3 \times 10^{-6}$ $\left(\mathrm{cm}^{2} / \mathrm{sec}\right)$ (Tyn-Calus)

$D_{\text {water/NMP }}^{o}=1.55 \times 10^{-8}\left(96.5^{0.27} / 18.0^{0.42}\right)$ $\left(298^{1.29} / 1.65^{0.92}\right) \quad\left(40.7^{0.125} / 72.5^{0.105}\right)=$ $15.8 \times 10^{-6}\left(\mathrm{~cm}^{2} / \mathrm{sec}\right)$ (Hayduk-Minhas). 